\title{
Adoption and use of mobile applications by local governments: the case of Portugal
}

\author{
Gonçalo P. Dias \\ GOVCOPP/IT, School of Technology and Management of Águeda, University of Aveiro \\ gpd@ua.pt
}

\begin{abstract}
The study presented in this article addresses the adoption and use of mobile applications by local governments in Portugal. The relevance of the study relates to the growing importance of mobile applications for e-government provision at the local level in the scope of the advent of smart sustainable cities and communities. Indeed, while smart and mobile technologies become increasingly available, it is fundamental to know how local governments are incorporating these technologies into daily practice. To perform the study, all the existing 308 Portuguese local governments were surveyed for the existence of official mobile applications. The general characteristics and functionalities of those applications were registered and categorized. Subsequently, descriptive statistics and mean variance, multiple linear regression, and clustering studies were conducted to analyze the data. Main findings include differences between determinants of adoption and use of mobile applications, difference between determinants for mobile applications use and the use of other types of e-government channels, and the existence of a hierarchy of use, with local governments privileging more informational functionalities to the detriment of the provision of services and the participation of citizens. It was also found that the functionalities offered by local governments through mobile applications seem to replicate functionalities already offered through other digital channels, neglecting the potential for the creation of innovative services by taking advantage of smart technology. Thus, a gap seems to exist between theoretical expectations and practice on the use of smart technologies by local governments. This study is the first to address adoption and use of mobile applications by local government in Portugal.
\end{abstract}

\section{CCS CONCEPTS}

- Applied computing $\rightarrow$ Computers in other domains; Computing in government; E-government; • Additional Keywords and Phrases: digital government, mobile applications, local government, Portugal;

\section{ACM Reference Format:}

Gonçalo P. Dias. 2021. Adoption and use of mobile applications by local governments: the case of Portugal. In 14th International Conference on Theory and Practice of Electronic Governance (ICEGOV 2021), October 06-08, 2021,

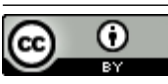

This work is licensed under a Creative Commons Attribution International 4.0 License.

ICEGOV 2021, October 06-08, 2021, Athens, Greece

(c) 2021 Copyright held by the owner/author(s).

ACM ISBN 978-1-4503-9011-8/21/10.

https://doi.org/10.1145/3494193.3494246
Athens, Greece. ACM, New York, NY, USA, 7 pages. https://doi.org/10.1145/ 3494193.3494246

\section{INTRODUCTION}

Local e-government can be defined as the use of Information and Communication Technologies (ICT) to "support government operations, provide public services and involve citizens at the local level" [1]. This definition encompasses different perspectives on the use of ICT by local governments, which include the provision of public services to citizens, the provision of public services to businesses, the purchase of products and services by local governments, the election of mayors and other representatives, the participation of citizens on the definition of public policies, and the digitalization of the internal processes of local government and of the transversal processes of the public administration in which they participate. In this study we address the two perspectives related to the interaction between local governments and citizens: the provision of public services to citizens; and the participation of citizens on the definition of public policies.

The interaction of local governments with citizens can be supported by various digital channels. The most studied of such channels include the Web $[2,3]$ and social media applications, such as Twitter, Facebook, LinkedIn, YouTube $[4,5,6]$. In the last few years, mobile applications gained prominence as an additional channel of local e-government provision, namely due to the spread of smart cities and communities initiatives.

The expression smart city "was first used in the 1990s" with a focus "on the significance of new ICT with regard to modern infrastructures within cities" [7]. Since then, the concept took on a broader meaning by including "other aspects of urban development, such as quality of life, economic growth, sustainability and participatory governance" $[8,9]$. This more comprehensive concept of smart cities "has the potential to overlap the previously existing concept of local e-government" [1], as citizens can use their mobile devices to interact with the local government and the city infrastructure. Indeed, as recently identified in [10], smart technology including smart phones and their mobile applications - allows a "series of micro-transactions" between citizens and governments, "encoded on the real-time landscape of the city" that goes beyond the traditional interactions between citizens and local governments. These types of interactions are typically not supported by using the Web or social media. Thus, new services and new types of participation can be achieved using smart technologies and, most notably, mobile applications.

Although the relevance of smart technologies and mobile applications for local government seems indisputable, it is important to recognize that many of the visions on that relevance come from a technological determinism perspective [11]. To complement 
these visions, it is important to know to what extent local governments are effectively adopting these new technologies, and for what purposes. However, studies addressing the effective use of smart technologies by local governments - and mobile application in particular - are very scarce. This study contributes to fill in this research gap by collecting and analyzing evidence from the Portuguese case.

The Portuguese case has previously been used to characterize the use of the Web [12] and of social media [13] by local governments. Thus, the selection of this case allows for comparison between the use of mobile applications and of other channels that are relevant for local e-government provision. Moreover, the country has a manageable, yet sufficiently large number of municipalities (308), which facilitates conducting empirical studies that consider the entire population (without resorting to sampling techniques), as is the case with this and the above-referenced studies.

The remaining of this paper is organized as follows: the related work is addressed in Section 2, within which the hypotheses of the study are also formulated; the data and the methods used in the study are presented in Section 3; the results of the statistical analyses are presented in Section 4; those results are discussed vis-à-vis the hypotheses of the study in Section 5; and, finally, the conclusions of the study are presented in Section 6.

\section{RELATED WORK AND HYPOTHESES}

\subsection{Determinants of local e-government}

A recent systematic literature review on the determinants of local e-government implementation has found that there is "a common set of determinants that explains local e-government implementation in general, and three other sets of determinants that contribute to differentiate each one of three e-government dimensions: e-transparency, e-participation, and e-services" [14]. The common set of determinants includes determinants associated with the internal characteristics of the local government (size, management capacity, financial capacity, technical capacity, leadership, organization form and culture, and previous experience), and determinants associated with the territorial jurisdiction of the local government (demography, socioeconomic dynamism, and Internet use). The differentiation between e-transparency, e-participation, and e-services occurs for additional determinants related to local politics (political orientation, political environment, and citizen participation) and to other environmental factors (stakeholders' pressure, and law, regulations, and directives) [14]. While based on 59 works published by various authors, the systematic review presented in [14] did not identify any primary studies on the determinants of mobile application use by local governments. Thus, it is important to assess to what extent these determinants are also relevant for the use of mobile applications at the local government level, and to what extend they vary with the different dimensions of use.

\subsection{The case of Portugal}

Several studies have addressed local e-government development in Portugal. Concerning the use of the Web, a study performed in 2010 for all the 308 Portuguese local governments concluded that "the resident population and the concentration of resources strongly potentiated the development of the supply side of local e-government", that "different socio-economic indicators are associated with different dimensions of e-government development", and that "the highest e-government maturities are observed in the coastal municipalities, which are the most populous and, simultaneously, have generically the best socio-economic indicators" [12]. It was also concluded that "municipalities tend to anticipate the development of simpler facilities in detriment of more complex ones or that may have more serious political or administrative implications", since local governments exhibiting lower levels of development mainly provide access to government information (e-transparency), while those exhibiting higher levels of development provide electronic services (e-services) and, specially, means for citizens to participate in public decisions (e-participation) [12]. Previous experience in digital cities projects, in particular, was found to be a relevant determinant of e-transparency. The same study was repeated in 2013, to conclude that "although noticeable improvements exist in every dimension, the gap between municipalities has also increased" [15].

More recently, a study on the use of Facebook by the Portuguese local governments concluded that the "levels of Facebook activity are significantly higher in larger and wealthier municipalities", and that social media "is mostly used by local governments to inform citizens rather than to promote later stages of e-participation" [13]. These results are consistent with those previously obtained for the use of the Web. Moreover, the study also concluded that "higher levels of social media activity appear in municipalities with more competitive local elections" and that "local governments tend to be concerned with the low levels of voter turnout, potentially resorting to social media as a powerful tool to increase civic engagement". The authors argue that this might be the consequence of political competition, namely because the "margins of victory seem to impact particularly on right-wing governments and, in the 2013 local elections, "the center-left Socialist Party won the majority of municipalities" [13].

Hypotheses of the study

The two studies on the Portugal case (Section 2.2) corroborate the existence of several of the determinants identified for the generic case (Section 2.1): size of local government; experience; demography; socioeconomic dynamism; participation level; and political competition. In order to test if these determinants are also relevant to explain the adoption and use of mobile applications by local governments in Portugal, we formulated the first hypothesis of the study:

- H1 - The adoption and use of mobile application by local governments in Portugal can be partially explained by size of local government, experience, demography, socioeconomic dynamism, participation level, political orientation, and political competition.

In the Portugal case, it was reported that different determinants can be associated with different e-government dimensions (Section 2.2), which is also coherent with what was reported for the global case (Section 2.1). Considering this previous evidence, we formulated the second hypothesis of the study:

- H2 - Different determinants contribute to explained different dimensions of the use of mobile applications by local governments in Portugal. 
Finally, the two studies performed for Portugal (Section 2.2) report a general tendency towards using the Web and social media mainly for informational purposes. In the case of the Web, it was also reported that a hierarchy of three e-government dimensions exist: "an initial stage of information provision, an intermediate state of service provision and a final stage of participation in public decisions" [12]. Taking this into consideration, we formulated the third hypothesis of the study:

- H3 - There is a hierarchy between the dimensions of mobile applications use by local authorities in Portugal, with the local governments prioritizing informational features over services and participation.

\section{METHODS}

\subsection{Primary data}

Primary data was collected by observing and categorizing the features offered by the mobile applications of the Portuguese local governments. Mobile applications were identified through references to them on the official websites of local governments. The official websites addresses were obtained from the website of the National Association of Portuguese Municipalities (www.anmp.pt). A total of 146 functional applications, belonging to 122 municipalities, were identified. These applications were downloaded and installed in compatible mobile devices and its general characteristics and functionalities were recorded in a specially developed database. Observations were made between 28 October and 11 November 2020 by nine groups of higher education students, each group being composed by three or four students.

Three rounds of observation took place. In the first round, each group of students installed and observed the applications of a group of randomly distributed local governments and proposed a categorization for the observed functionalities. The categorizations proposed by the several groups were then harmonized by the author. In the second round of observation, the types of functionalities offered by the applications were recorded according to the harmonized categorization. Finally, in the third round of observation, the local governments were randomly redistributed among groups and each group verified the correctness of the previously made observations. Any disparities were resolved by the author by directly observing the applications concerned.

The general characteristics of the mobile applications that were observed included three parameters: inclusion of a privacy policy manifest; availability of an authentication facility; and availability of versions of the application for Android, IOT and/or other platforms. According to the harmonized characterization, three dimensions of functionalities were considered: information (message from the Mayor; interactive map; municipal news; public notices and alerts; useful contacts; open pharmacies; weather forecast; calendar of events; tourist information; companies, associations and other local entities; public transports; COVID-19 pandemic; and other informational services); services (access to online services; access to open data; online desk; ticket sales; communication of water consumption readings; schedule of large trash pickup; and other services); and participation (communication of incidents; public participation; participatory budgeting; suggestions and complaints; and other forms of participation).

\subsection{Secondary data}

In order to test hypothesis H1 (The use of mobile application by local governments in Portugal can be partially explained by size of local government, experience, demography, socioeconomic dynamism, participation level, and political competition) and H2 (Different determinants contribute to explained different dimensions of the use of mobile applications by local governments in Portugal), data on local governments and their territorial jurisdictions was obtained from secondary sources. The variable names, the transformations applied, and the indicators used, their reference year, and their source are presented in Table 1. Logarithmic transformations were performed for the variables that exhibit an exponential distribution (size, and demography). This was made to assure that all variables had an approximately normal distribution, which was relevant for some of the subsequent analyses.

\subsection{Statistical analyses}

In order to identify possible determinants of adoption of mobile applications, the Portuguese local governments were divided in two groups: (i) local governments not offering any mobile application; and (ii) local governments offering one or more application. A series of T-Tests were then performed to identify significant mean differences between the two groups for each variable considered in the study (see Table 1). When this happened, those variables were tested as possible determinants by computing binomial logistic regressions.

In order to analyze mobile application use, only the local governments offering one or more mobile applications were considered. For these, a series of statistical analyses were carried out:

- First, a descriptive statistical analysis was performed to characterize the use of the mobile applications according to their general characteristics, the functionalities they offer, and the categorization of those functionalities.

- Second, a multiple linear regression analysis with the number of functionalities offered as dependent variable and all the other variables considered in the study as independent variables was computed, and then refined by withdrawing the non-significant variables, to identify possible determinants of mobile application use by Portuguese local governments (Hypothesis H1).

- Third, a K-mean clustering was computed using the three dimensions of functionality (information, services, and participation) as the clustering variables, to test if a hierarchy between the three dimensions of analysis exists (Hypothesis H3).

- Fourth, the same clusters were used to test if different determinants can be associated with different dimensions of analysis (Hypothesis H2), by running a series of ANOVA studies against the independent variables considered in the study.

\section{RESULTS}

\subsection{Adoption analysis}

Table 2 presents the results of the T-Tests performed to identify if significant mean differences between adopters and non-adopters of 
Table 1: Variable names and types and the original indicators used, their reference years, and their source.

\begin{tabular}{lllll}
\hline Variable name & Transf. & Original indicator & Year & Source \\
Size & $\log 10$ & Number of employees of the local government & 2020 & National Statistical Institute \\
Experience & & Digital government index & 2013 & Dias e Gomes, 2014 [15] \\
Demography & $\log 10$ & Estimated population & 2018 & National Statistical Institute \\
Dynamism & & Purchasing power & 2017 & National Statistical Institute \\
Participation & & Turnover in local elections & 2017 & National Elections Commission \\
Competition & & Margin of victory of ruling party or coalition & 2017 & National Elections Commission \\
\hline
\end{tabular}

Table 2: Results of the T-Tests for adoption of mobile applications.

\begin{tabular}{|c|c|c|c|c|c|}
\hline Variable & Group & $\mathrm{N}$ & Mean & $\begin{array}{l}\text { Standard } \\
\text { deviation }\end{array}$ & $\begin{array}{l}\text { T-Test } \\
\text { Significance }\end{array}$ \\
\hline \multirow[t]{2}{*}{ Size } & adopters & 122 & 478 & 812 & 0.141 \\
\hline & non-adopters & 186 & 375 & 441 & \\
\hline \multirow[t]{2}{*}{ Experience } & adopters & 122 & 5.57 & 2.17 & 0.018 \\
\hline & non-adopters & 186 & 5.00 & 1.80 & \\
\hline \multirow[t]{2}{*}{ Demography } & adopters & 122 & 36215 & 812 & 0.448 \\
\hline & non-adopters & 186 & 31497 & 441 & \\
\hline \multirow[t]{2}{*}{ Dynamism } & adopters & 122 & 82.75 & 22.05 & 0.203 \\
\hline & non-adopters & 186 & 79.03 & 15.43 & \\
\hline \multirow[t]{2}{*}{ Participation } & adopters & 122 & 0.60 & 0.09 & 0.455 \\
\hline & non-adopters & 186 & 0.61 & 0.08 & \\
\hline \multirow[t]{2}{*}{ Competition } & adopters & 122 & 25.68 & 15.77 & 0.267 \\
\hline & non-adopters & 186 & 24.30 & 15.74 & \\
\hline
\end{tabular}

Table 3: Classification table of the binomial logistic regression for adoption using experience as the independent variable.

\begin{tabular}{lllll}
\hline Variable & Predicted as non-adopters & Predicted as adopters & Total & Percentage correct \\
non-adopters & 181 & 5 & 186 & $97.3 \%$ \\
adopters & 109 & 13 & 122 & $10.7 \%$ \\
Total & 290 & 18 & 308 & $63.0 \%$ \\
\hline
\end{tabular}

mobile applications exist. As is visible, the only statistically significant mean difference occurs for the variable Experience $(\mathrm{p}<0.05)$. Thus, this is the only variable that can plausibly contribute to explaining adoption. However, when used as the independent variable in a binomial logistic regression, this variable allows for the correct classification of only $10.7 \%$ of the adopters (see Table 3 ), which is not enough to consider it as a good predictor and, consequently, a good determinant of mobile application adoption. Thus, it is not possible to identify any good determinants of mobile application adoption by the Portuguese local governments among the investigated variables.

\subsection{Descriptive analysis}

In November 2020, 122 local governments in Portugal (39.6\%) had at least a functioning official mobile application. Table 4 presents the number and percentage of local governments that exhibit each characteristic. The characteristics are organized in four categories: general characteristics; informational functionalities (information); provision of services (services); and functionalities allowing the participation of citizens (Participation). Relating general characteristics, only $22 \%$ of the municipalities publicize their privacy policies thorough those applications (55\% of the municipalities having mobile applications), and only $25 \%$ provide an authentication facility ( $62 \%$ of the municipalities having mobile applications). The most supported platform is Android, with 98\% of the municipalities having applications supporting it, followed by IOS (72\%). Other platforms are supported only by $9 \%$ of the municipalities having mobile applications.

Concerning the most common functionalities, $32 \%$ of the municipalities provide information to tourists, $31 \%$ provide calendars of cultural and other events, $30 \%$ publicize local useful contacts, and $28 \%$ publish news related to the local municipality. All other functionalities are offered by only a quarter or less of the local governments. As is visible in the table, there is a larger diversity of items in the information dimension and those are typically offered by more local governments than for the other dimensions. Event so, there are relatively high percentage of municipalities offering functionalities such as communications of incidents and submission of suggestions and complaints that, although classified in the 
Table 4: Number and percentage of municipalities where the analyzed items were observed.

\begin{tabular}{|c|c|c|c|}
\hline Dimension & Item & $\begin{array}{l}\text { Number of local } \\
\text { governments }\end{array}$ & $\begin{array}{l}\text { Percentage of local } \\
\text { governments }\end{array}$ \\
\hline \multirow[t]{5}{*}{ general } & privacy policy & 67 & $22 \%$ \\
\hline & authentication facility & 76 & $25 \%$ \\
\hline & available for Android & 120 & $39 \%$ \\
\hline & available for IOS & 88 & $29 \%$ \\
\hline & available for other platforms & 28 & $9 \%$ \\
\hline \multirow[t]{13}{*}{ Information } & message from the Mayor & 63 & $20 \%$ \\
\hline & interactive map & 74 & $24 \%$ \\
\hline & municipal news & 85 & $28 \%$ \\
\hline & public notices and alerts & 46 & $15 \%$ \\
\hline & useful contacts & 91 & $30 \%$ \\
\hline & open pharmacies & 55 & $18 \%$ \\
\hline & weather forecast & 60 & $19 \%$ \\
\hline & calendar of events & 94 & $31 \%$ \\
\hline & tourist information & 99 & $32 \%$ \\
\hline & companies, and other local entities & 25 & $8 \%$ \\
\hline & public transports & 20 & $6 \%$ \\
\hline & COVID-19 pandemic & 18 & $6 \%$ \\
\hline & other informational services & 31 & $10 \%$ \\
\hline \multirow[t]{7}{*}{ Services } & access to online services & 31 & $10 \%$ \\
\hline & access to open data & 22 & $7 \%$ \\
\hline & online desk & 9 & $3 \%$ \\
\hline & ticket sales & 3 & $1 \%$ \\
\hline & communication of water consumption & 29 & $9 \%$ \\
\hline & large trash pickup schedule & 37 & $12 \%$ \\
\hline & other services & 20 & $6 \%$ \\
\hline \multirow[t]{5}{*}{ Participation } & communication of incidents & 76 & $25 \%$ \\
\hline & public participation & 10 & $3 \%$ \\
\hline & participatory budgeting & 13 & $4 \%$ \\
\hline & suggestions and complaints & 65 & $21 \%$ \\
\hline & other forms of participation & 3 & $1 \%$ \\
\hline
\end{tabular}

Table 5: Number and percentage of local government having mobile applications witch exhibit characteristics in each dimension and frequency, range, median, mean, and standard deviation of observations made.

\begin{tabular}{llllllll}
\hline Dimension & $\begin{array}{l}\text { Number of local } \\
\text { governments }\end{array}$ & $\begin{array}{l}\text { Percentage of local } \\
\text { governments }\end{array}$ & Frequency & Range & Median & $\begin{array}{l}\text { Mean } \\
\text { Standard } \\
\text { deviation }\end{array}$ \\
Total & 122 & $40 \%$ & 1078 & $1-19$ & 9.5 & 8.84 & 4.93 \\
Information & 117 & $38 \%$ & 760 & $1-12$ & 7 & 6.50 & 2.82 \\
Services & 66 & $21 \%$ & 151 & $1-5$ & 2 & 2.29 & 1.16 \\
Participation & 83 & $27 \%$ & 167 & $1-5$ & 2 & 2.01 & 0.77 \\
\hline
\end{tabular}

participation dimensions, do not have much complex political or administrative implications.

Table 5 shows the number and percentage of municipalities that offer at least one functionality, in total and for each dimension, as well as the frequency, the range, the median, the mean, and the standard deviation of the observations. From the Table it is evident that municipalities tend to favor informational functionalities to the detriment of services and participation. It is also noticeable that although there are more municipalities offering at least a participation functionality than at least a service, the mean for the number of services offered by each local government is higher than for participation functionalities.

\subsection{Regression analysis}

Table 6 shows the results of two multiple linear regression analyses. Both regressions models use the total number of observation (regardless of the dimension of analysis) as the dependent variable. The first regression model uses all variables considered in the study (see Table 1) as independent variables and the second regression model uses only those variables that were significant in the first 
Table 6: Statistics for the multiple linear regression models.

\begin{tabular}{llllll}
\hline Dimension & Model 1 & & & Model 2 & \\
& B & Std. Error & Sig. & B & Std. Error \\
Constant & 2,757 & 8.126 & 0.735 & 0.323 & 3.585 \\
Size (log) & -11.284 & 2.921 & 0.000 & -10.157 & 2.622 \\
Experience & 0.063 & 0.220 & 0.775 & & 0.928 \\
Demography (log) & 7.846 & 2.080 & 0.000 & 7.947 & 0.000 \\
Dynamism & 0.018 & 0.031 & 0.564 & & \\
Participation & -0.633 & 6.521 & 0.923 & & \\
Competition & -0.026 & 0.029 & 0.366 & & \\
$\mathrm{R}^{2}$ of the model & 0.142 & & & 0.132 & \\
Sig. of the model & 0.006 & & & 0.000 & \\
\hline
\end{tabular}

Table 7: Number of cases, clusters centers, and frequency, range, median, mean, and standard deviation of all observations, regardless of the dimension.

\begin{tabular}{|c|c|c|c|c|c|c|c|c|}
\hline \multirow[t]{2}{*}{ Cluster } & \multirow[t]{2}{*}{ Number of cases } & \multicolumn{3}{|l|}{ Cluster centers } & \multicolumn{4}{|c|}{ Total number of functionalities } \\
\hline & & information & services & participation & range & median & mean & std. error \\
\hline 1 & 36 & 2 & 0 & 0 & $1-7$ & 3 & 2.92 & 1.610 \\
\hline 2 & 47 & 7 & 1 & 1 & $5-12$ & 9 & 8.68 & 2,323 \\
\hline 3 & 39 & 9 & 7 & 2 & $12-19$ & 14 & 14.46 & 1.971 \\
\hline
\end{tabular}

regression model. Both models are significant at the 0.05 level and have no collinearity problems.

Using Model 2, it can be concluded that the conjunction of the size of the municipality, as measured by the logarithm of the number of workers, and the demography of the local government jurisdiction, as measured by the logarithm of the number of inhabitants, constitute a good predictor of mobile application use by Portuguese local governments, explaining $13.2 \%$ of its variance $\left(\mathrm{R}^{2}=0.132\right)$. Adding other variables (as is the case in Model 1) does not add much explanatory power to the model. Thus, the number of functionalities offered by the Portuguese local governments through mobile applications is partially explained by the population of their territorial jurisdictions, moderated by their number of workers.

\subsection{Cluster analysis}

Table 7 shows the number and percentage of local governments per cluster, the cluster centers (considering the dimensions), and frequency, range, median, mean, and standard deviation of all observations (regardless of the dimension). Three clusters were used based on previous dendrogram analysis. From the table, it is evident that a hierarchy exists between the three dimensions of analysis. Indeed, local governments that offer fewer functionalities tend to offer only informational functionalities, while the local government that offer a higher number of functionalities still tend to favor the disclosure of information in relation to the provision of services and the offer of participation features.

To complement the analysis, several ANOVA studies were performed to test if significant mean differences exist between the three clusters for the variables considered in the study (see Table 1). All these studies were not significant, meaning that the considered variables are not relevant for determining the identified clusters.

\section{DISCUSSION}

The results presented in the previous section demonstrate that previous experience in implementing local e-government initiatives is significant to explain mobile application adoption by local governments, even so it does not constitute a good predictor of that phenomenon. This means that previous experience can be considered as a determinant of mobile application, despite having a very low explanatory power. Considering mobile applications use, it was found that, when combined, the logarithm of the number of workers and the logarithm of the resident population are significant determinants of the number of functionalities offered, explaining about $13.2 \%$ of the dependent variable variance. Thus, some but not all the independent variables considered in the study act as determinants of mobile application use and, consequently, hypothesis H1 (The adoption and use of mobile application by local governments in Portugal can be partially explained by size of local government, experience, demography, socioeconomic dynamism, participation level, and political competition) was only partially validated.

It was not possible to demonstrate that the independent variables considered in the study contribute to differentiate the three clusters of municipalities that were established by using the three dimensions of functionality (information, services, and participation). Thus, it is not possible to state that there are different determinants for the different dimensions of analysis and, consequently, Hypothesis H2 (Different determinants contribute to explained different dimensions of the use of mobile applications by local governments in Portugal) was not validated by the study.

Finally, the analysis of the centers of the clusters when combined with the cluster's statistics for the number of functionalities offered allow the conclusion that there is a hierarchy between the three dimensions of mobile application use, with a clear prominence of information over services and of services over participation. 
Consequently, Hypothesis H3 (There is a hierarchy between the dimensions of mobile applications use by local authorities in Portugal, with the local governments prioritizing informational features over services and participation) was fully validated.

\section{CONCLUSIONS}

Mobile applications are offered by only $40 \%$ of all the Portuguese local governments. Previous experience on implementing local e-government initiatives through the Web has proved to be a significant determinant of mobile application adoption by local governments, despite its very low explicative power. Other determinants that were previously found relevant for local e-government development and social media use by local governments, such as size, demography, socioeconomic dynamism, participation level, and political competition, were not found relevant to explain mobile application adoption. Although size and demography are not relevant for adoption, they contribute to explain the number of functionalities offered through mobile applications by the local governments that adopt them. Thus, there seems to be a difference between determinants of adoption and determinants of use, which might be the consequence of the different phases of e-government implementation that may be at stake, namely adoption and institutionalization [14].

As was the case for previous studies on local e-government development in Portugal, it was found that there is a hierarchy between different dimensions of the functionalities offered through mobile applications, with local governments prioritizing the publication of information in detriment of service provision and the provision of services in detriment of participation. This supports the conclusion previously reported for the use of Web by local governments in [12], that local governments "tend to anticipate the development of simpler facilities in detriment of more complex ones or that may have more serious political or administrative implications". Indeed, event when services and participation functionalities are at stake, they tend to be rather simple, including, for example, communication of water consumptions and large trash pickup schedule, in the case of services, and communication of incidents and suggestions and complaints, in the case of participation.

Above all, it was found that the functionalities that are offered by local governments do not take much advantage of the innovative features supported by mobile devices. In general, it seems that local governments simply reproduce features that are already available through other channels, such as the Web and social media, neglecting the potential of mobile devices for supporting new types of services, as is profusely discussed in the literature, namely in the context of smart cities and communities. Thus, it seems that a relevant gap between theoretical expectations and effective practice on the use of smart technologies by local e-government exists, at least in Portugal and in the current state of local e-government development.

\section{ACKNOWLEDGMENTS}

The author would like to thank the students enrolled in the 2020/21 edition of the curse on Electronic Government at the University of Aveiro for their cooperation in the collection of the data that supported the study. This work was financially supported by the research unit on Governance, Competitiveness and Public Policy (UIDB/04058/2020) + (UIDP/04058/2020), funded by national funds through FCT - Fundacão para a Cie^ncia e a Tecnologia.

\section{REFERENCES}

[1] G. P. Dias. 2019. Are smart cities reshaping local e-government research? In Proceedings of the 14th Iberian Conference on Information Systems and Technologies (CISTI). IEEE, Coimbra, Portugal, 1-4. https://doi.org/CISTI.2019.8760778

[2] M. J. Moon. 2002. The evolution of E-government among municipalities: Rhetoric or reality? Public Admin. Rev., 62, 4, 424-433. https://doi.org/10.1111/0033-3352. 00196

[3] D. F. Norris, and C. G. Reddick. 2013. Local e-government in the United States: Transformation or incremental change? Public Admin. Rev., 72, 1, 165-175. https: //doi.org/10.1111/j.1540-6210.2012.02647.x

[4] E. Bonsón, L. Torres, S. Royo, and F. Flores. 2012. Local e-government 2.0: Social media and corporate transparency in municipalities. Gov. Infor. Q., 29, 2, 123-132. https://doi.org/10.1016/j.giq.2011.10.001

[5] K. Mossberger, Y. Wu, and J. Crawford. 2013. Connecting citizens and local governments? Social media and interactivity in major U.S. cities. Gov. Infor. Q., 30, 4, 351-358. https://doi.org/10.1016/j.giq.2013.05.016

[6] E. Bonsón, S. Royo, and M. Ratkai. Citizens' engagement on local governments' Facebook sites. An empirical analysis: The impact of different media and content types in Western Europe. Gov. Infor. Q., 32, 1, 52-62. https://doi.org/10.1016/j.giq. 2014.11.001

[7] G. P. Dias. 2018. Smart cities research in Portugal and Spain. In Proceedings of the 13th Iberian Conference on Information Systems and Technologies (CISTI). IEEE, Caceres, Spain, 1-6. https://doi.org/10.23919/CISTI.2018.8399295.

[8] T.M. Chen. 2011. Smart grids, smart cities need better networks. IEEE Network, 24, 2, 2-3. https://doi.org/10.1109/MNET.2010.5430136

[9] A. Caragliu, C. del Bo, and P. Nijkamp. 2011. Smart cities in Europe. J. Urban Technol., 18, 2, 65-82. https://doi.org/10.1080/10630732.2011.601117

[10] P. A. Johnson, P. J. Robinson, and S. Philpot. 2020. Type, tweet, tap, and pass: How smart city technology is creating a transactional citizen. Gov. Information Q., 37, 1, 101414. https://doi.org/10.1016/j.giq.2019.101414

[11] J. Nograšek, and M. Vintar. 2014. E-government and organisational transformation of government: Black box revisited? Gov. Information Q., 31, 1, 108-118. https://doi.org/10.1016/j.giq.2013.07.006

[12] G. P. Dias, and M. Costa. 2013. Significant socio-economic factors for local egovernment development in Portugal. Electronic Government, 10, 3/4, 284-309. https://doi.org/10.1504/EG.2013.058785

[13] P. Silva, A. F. Tavares, T. Silva, and M. Lameiras. 2019. The good, the bad and the ugly: Three faces of social media usage by local governments. Gov. Information Q., 36, 3, 469-479. https://doi.org/10.1016/j.giq.2019.05.006

[14] G. P. Dias. 2020. Determinants of e-government implementation at the local level: an empirical model. Online Inform. Rev., 44, 7, 1307-1326. https://doi.org/10.1108/ OIR-04-2020-0148

[15] G. P. Dias, and H. Gomes. 2014. Evolution of local e-government maturity in Portugal. In Proceedings of the 9th Iberian Conference on Information Systems and Technologies (CISTI). IEEE, Barcelona, Spain, 6877041. https://doi.org/10. 1109/CISTI.2014.6877041 